\title{
LA RELIGIÓN Y SU LUGAR EN LA SOCIOLOGÍA
}

Prisciliano Cordero del Castillo *

\section{LA RELIGIÓN COMO OBJETO DE LA SOCIOLOGÍA.}

La religión, en su naturaleza y en sus manifestaciones, es un fenómeno tan complejo que no puede ser comprendido por una sola ciencia. Como expresión de un mensaje sobrenatural, la religión es objeto de la teología. La filosofía trata, por su parte, de profundizar en su naturaleza a través del razonamiento.

Las ciencias empíricas que estudian el hecho religioso se ocupan de aspectos concretos: su dinámica a lo largo de la historia (historia de las religiones), su influjo en el campo psíquico (psicología de la religión), sus aspectos sociales (sociología de la religión), etc.

Uno de los pocos paradigmas sociológicos que cuenta con el consenso general de la mayoría de los sociólogos de la religión es considerar a ésta no en su esencia, sino en sus manifestaciones externas, como un hecho social. Hoy, después de los estudios de Max Weber sobre la ética protestante calvinista y el desarrollo del capitalismo, nadie duda que la religión sea configurada y condicionada por la sociedad, al mismo tiempo que ésta, la sociedad, es condicionada por la religión.

En este mismo sentido se manifiesta Fernández Fernández,F. (1996:77) cuando dice que «el binomio «Religión-Sociedad», hecho religioso y contexto social, se encuentra siempre interrelacionado y es, por su propia situación y configuración social, interdependiente» .

*Profesor Titular de Sociología. Universidad de León. 
En coherencia con lo anterior, H.W. Goddijn (1973:30) afirma que no es posible ser un buen sociólogo de la religión sin ser, al mismo tiempo, un buen sociólogo generalista; esto es, un buen conocedor de toda la llamada «Teoría sociológica». Pues, cuando el sociólogo hace objeto de su investigación al «hecho religioso», en cualquier nivel y dimensión que sea, se sirve de los mismos métodos y técnicas características de la Sociología General. Es decir, investiga la religiosidad e irreligiosidad en su interrelación con el resto de las variables integrantes de «lo social».

Esta interdependencia se puede observar al analizar los últimos cambios registrados en España. Se puede comprobar cómo en España en los últimos años ha cambiado la religión, la forma de entender y vivir la religión, a medida que cambiaba la sociedad y viceversa. Por ejemplo, el hecho religioso de la caída de las vocaciones sacerdotales, que suele explicarse desde la teología o la moral, diciendo que es resultado de la falta de fe, de la pérdida de la moral y las costumbres, del abandono de Dios a su pueblo o de éste a Aquel, etc. También puede explicarse desde la sociología. Pueden darse otras razones que, sin negar las anteriores de naturaleza teológica, expliquen la falta de vocaciones como un hecho social, como efecto de diversos cambios socio-culturales y económicos.

La perspectiva sociológica nos hace ver los acontecimientos históricos de este manera: hasta los años de la postguerra y la industrialización de los años 60, el mundo rural español estaba superpoblado; las familias campesinas, con una tasa de natalidad muy elevada ( $4-5$ hijos de media por familia), no contaban con recursos suficientes para estratificar a todos sus hijos; la misma sociedad ofrecía pocas alternativas a las nuevas generaciones. Así, pues, los jóvenes rurales hasta la industrialización de los años 60 no tenían más posibilidades que: unos quedar en casa con los padres, otros emigrar y otros entrar en los seminarios y casas religiosas, donde muchos de ellos llegaron a sacerdotes, aumentando el número de vocaciones.

Por supuesto que, aparte de este razonamiento sociológico, hay que tener en cuenta los valores religiosos dominantes en la sociedad rural española de aquel entonces, en donde el tener un hijo sacerdote o religioso era considerado un gran valor, además de una ayuda económica.

Pero la realidad social española hoy ha cambiado profundamente: el campo está despoblado, la familia ha reducido drásticamente el número de hijos (la tasa media de natalidad en el 2000 es de 1,07 hijos por familia), la situación económica y cultural ha mejorado sensiblemente y además la sociedad, ahora laica, ofrece muchas más posibilidades de formación y promoción social.

En estas circunstancias no es de extrañar que las vocaciones sacerdotales y religiosas hayan caído; más aún teniendo en cuanta los cambios de tipo religioso que también se han registrado en la familia y en la sociedad.

La sociología no niega el origen sobrenatural de los hechos religiosos, tampoco lo afirma, simplemente analiza estos fenómenos desde un punto de vista empírico que, lógicamente, es distinto al filosófico o al teológico. 
Para confirmar la interrelación del binomio Religión-Sociedad, se suele citar el estudio ya mencionado de M. Weber: «La ética protestante y el espíritu del capitalismo», según el cuál la ética calvinista, en definitiva la religión, habría sido el desencadenante del capitalismo moderno; tesis esta, por otra parte, opuesta al determinismo económico de Marx.

Todo esto demuestra que el hecho religioso es en sí mismo un hecho social, tiene una repercusión social, y que la sociedad, a su vez, determina el hecho religioso.

La religión, además de elementos trascendentes y mistéricos, cuenta también con elementos observables, medibles y comparables y, como tales, pertenecientes al campo de análisis de la sociología. La religión en su origen y en sus vivencias personales e íntimas no puede ser reducida al campo experimental; es objeto de análisis de otras ciencias, tales como la teología y la filosofía. Pero en sus aspectos y manifestaciones externas: ritos, valores, exigencias éticas, visión del mundo y del hombre, existencia de unas estructuras, de una jerarquía, de un orden social, etc., es objeto específico de la sociología como ciencia, que se ocupa de la conducta humana, de la interacción y de las estructuras sociales.

En resumen, la religión es un fenómeno social y por lo mismo objeto de la sociología. Así es como lo han entendido los clásicos de la sociología y muchos autores contemporáneos.

\section{PERSPECTIVAS MÁS SIGNIFICATIVAS DEL ANÁLISIS SOCIOLÓGICO DE LA RELIGIÓN}

Dada la especificidad del hecho religioso y las serias dificultades que algunos encuentran para considerar la religión como hecho social, en la breve historia de la sociología como ciencia se han dado múltiples posicionamientos o perspectivas de análisis de los fenómenos religiosos. La sociología clásica de la religión de Weber, Troeltsch, Sombart y Scheler, entre otros, tenía como objetivo principal la explicación del mundo moderno a partir de la religión y más concretamente del cristianismo. En la actualidad, la sociología de la religión trata más bien de entender la interacción entre religión y sociedad.

Los diversos posicionamientos sociológicos frente a la religión pueden ser agrupados, como hace M. Hill (1976:22), en las siguientes perspectivas básicas:

a) En un extremo se sitúan aquellos que consideran los fenómenos religiosos como situados más allá de toda posibilidad de análisis por parte del entendimiento humano y, por consiguiente, fuera del alcance de la sociología. Este posicionamiento entraña una perspectiva teológicamente conservadora y fundamentalista, en la que la religión es considerada como una experiencia y una actividad humana autónoma, independiente de otras parcelas humanas como la economía y la política, algo que no se puede alcanzar desde la sociología. Esta posición elimina al sociólogo, sitúa todo lo religioso fuera del alcance de la investigación sociológica. Un ejemplo de esta forma de acercarse a la religión lo tenemos en los sociólogos provenientes de la teología, como Le Bras y W. Stark, que suelen tomar un tono apologético al estudiar el catolicismo. 
b) La segunda perspectiva, situada en el extremo opuesto, da por supuesto que las creencias religiosas no sólo no están fuera del alcance del conocimiento humano, sino que, en gran medida, son un mero producto social en el que se sitúan, de forma que es posible explicar exhaustivamente su alcance y significado mediante la ciencia socio-económica.

En este posicionamiento va implícita la idea de que la religión nunca puede ser algo «real», en el sentido de que exista algo situado más allá de cuanto puedan explicar las ciencias humanas. Consecuencia de esta argumentación es que las supuestas actividades religiosas y sus objetivos pueden ser reducidos a formulaciones empíricas relativas al mundo social.

Esta postura tiene una larga tradición en la sociología. Los primeros sociólogos más destacados, como Augusto Comte, Herbert Spencer, Edward Tylor, James Frazer, no podían encontrar un puesto para la religión a no ser que ésta se redujera a meros términos empíricos. En esta misma línea se sitúan otros autores posteriores, como Karl Marx y Sigmund Freud.

c) La tercera perspectiva se sitúa en una postura intermedia entre las dos anteriores. Desde este posicionamiento se rechaza, por una parte, el argumento de que la religión no es accesible al análisis de las técnicas empíricas de la sociología. La razón fundamental es que la experiencia religiosa se manifiesta en actitudes y en orientaciones, en creencias y en compromisos éticos que ejercen una notable influencia en los modos de vida de los individuos y en las instituciones. Ahora bien, si la sociología trata de comprender significativamente la actividad y la organización sociales a partir de un cuerpo de conocimientos teóricos y de categorías sistemáticas, no hay ninguna razón para excluir los fenómenos religiosos, como un aspecto específico de la actividad humana, del campo de análisis sociológico.

Por otra parte, si la sociología tiene por objeto comprender significativamente la acción social, esto quiere decir que debe incluir necesariamente todo aquello que resulte significativo para los sujetos de la acción social, aunque en algunos casos lo significativo no sea empíricamente «visible».

Otro planteamiento del desarrollo de la sociología de la religión es el que hacen G. Milanesi y J. Bajzek (1993:7-11). En primer lugar parten del positivismo de Comte, en el que la futura «religión de la humanidad» puede ser objeto de la ciencia sociológica, y de los postulados de Spencer sobre la religión del «incognoscible», de los «residuos» que escapan al análisis científico, de los hechos «ulteriores» que escapan a la lógica evolucionista y de los elementos «arracionales» que emergen en el contexto de las relaciones sociales. Mencionan luego las escuelas evolucionista, antievolucionista y funcionalista, para terminar reconociendo a Durkheim y a Weber como los dos grandes teóricos de la sociología de la religión.

En segundo lugar estudian la crítica de la religión en el pensamiento posthegeliano, distinguiendo entre: a) La izquierda hegeliana, representada por Feuerbach, Marx y Engels, a quienes no consideran sociólogos de la religión, pero 
sí les reconocen el haber intentado dar una interpretación sociológica de los fenómenos religiosos. b) La derecha hegeliana, que se caracteriza por dedicarse a la búsqueda de nuevos fundamentos teóricos del fenómeno religioso, dando origen al nacimiento de una sociología religiosa. Forman parte de esta corriente F. Tönnies, Max Weber, G. Simmel y E. Troeltsch, entre otros.

En un tercer momento sitúan la corriente sociológica anglo-americana, que intenta aplicar los principios metodológicos del funcionalismo a los problemas religiosos. En esta línea estarían las aportaciones de T. Parsons, J.M. Yinger y Kingsley David.

Finalmente recogen la actitud de los científicos católicos frente a la sociología de la religión. En un primer momento se dio una actitud de oposición, fundada en la desconfianza que tenían en el positivismo, el relativismo y el reduccionismo que atribuían a los planteamientos de Comte, Spencer y Durkheim. Pronto pasan a aceptar el método positivo como instrumento válido para el diagnóstico social y, en consecuencia, a aceptar la sociología. Pero es sólo a partir de los estudios de G. Le Bras que la sociología de la religión recibe las aportaciones de los católicos.

Así, pues, el estudio de la religión por parte de la sociología, desde su origen hasta los estudios más recientes, ha sido planteado desde distintos enfoques y por distintos autores, de los que pasamos a analizar los mas significativos:

\section{AUTORES MÁS INFLUYENTES EN LA SOCIOLOGÍA DE LA RELIGIÓN:}

\section{Augusto Comte}

Con su famosa «Ley de los tres estadios», Comte quiso elevar el positivismo, el cienticismo, a la categoría de religión. Comte entiende que cada estadio implica la búsqueda, por parte del hombre, de una explicación de las cosas que le rodean.

Así, el estadio teológico es el punto de partida de la búsqueda humana de la esencia de las cosas: ?de donde proceden?, ?para qué sirven?. En este proceso, el hombre llega a la búsqueda de lo absoluto, del sobrenatural, bien sean dioses en el politeísmo o un solo Dios en el monoteísmo, que es quien crea y asigna sus fines a las cosas creadas. El desarrollo último de este estadio llega al monoteísmo, a la admisión de una única divinidad que lo explica todo.

Las primitivas explicaciones mítico-religiosas, estadio teológico, según Comte, habían sido sustituidas por explicaciones filosóficas, estadio metafísico, por fuerzas abstractas que explican las causas originales y los propósitos de las cosas del mundo. Este es un estadio transitorio entre el teológico y el positivo, y el menos importante de los tres.

El estadio metafísico, a su vez, ha sido sustituido por el estadio positivo, el último y más importante en el sistema comteano. En el estadio positivo el hombre abandona su búsqueda de la razón de las cosas para fijarse en los fenómenos en sí mismos, en las relaciones existentes entre ellos, que es lo único que el hombre 
puede conocer. Se abandonan las ideas no científicas, como son los seres sobrenaturales, para centrarse en la búsqueda de las leyes naturales que gobiernan todos los fenómenos, como dice G. Ritzer (1993:95-97)).

Augusto Comte, en su teoría, que alcanzó gran difusión en la sociedad del siglo XIX, daba por supuesto que la ciencia desplazaría a la religión y que en el futuro desaparecerían los estadios teológico y metafísico y se implantaría totalmente el estadio positivo, como efecto liberador de la ciencia moderna.

Sin embargo, Comte es consciente del papel social de la religión, por lo que, entrando en contradicción con su propia teoría, se propone crear una nueva «Religión de la Humanidad», que impulse a los hombres hacia el altruismo, el sacrificio y la generosidad, y que tenga como objeto de culto la raza humana.

Comte fracasó en su intento de crear la nueva religión y se le ha acusado de defender una teoría contradictoria, pues habla de la necesidad de prescindir de la religión y de la filosofía para explicar la historia y luego él acude a la religión, a una nueva religión natural, para dar respuesta al momento histórico en que vive; sin embargo hay que reconocerle un cierto grado de intuición, pues en la religiosidad del siglo XX se ha impuesto el culto al destino universal del hombre, como él había previsto.

\section{Emile Durkheim}

Durkheim podría ser considerado como el representante clásico de quienes renuncian a definir la religión por motivos metodológicos y gnoseológicos. Sólo se pregunta por el significado estructural y funcional que para una sociedad tienen los fenómenos que se presentan como religiosos. Durkheim contrapone las «cosas sagradas» a las «cosas profanas». Las cosas sagradas no se distinguen de las profanas por sus cualidades intrínsecas, sino por las actitudes humanas hacia ellas, porque son separadas por una actitud de respeto, con lo cual se las rodea de tabúes y restricciones, se las sacraliza.

Para el análisis sociológico de Durkheim, la religión, las «cosas sagradas», son significativas en la medida en que se manifiestan y ejercen un influjo en la sociedad. El origen de la religión está en el carácter regulador de la actuación y del comportamiento sociales y entiende que la conducta religiosa no es más que una conducta social integradora.

La religión es un fenómeno universal que aparece en todas las sociedades conocidas y, como fenómeno universal, la sociología no sólo tiene el derecho, sino también el deber de incluirla en su campo de análisis. Concretamente uno de los trabajos más importantes de Durkheim (1899) sobre la sociología de la religión se ocupa de la definición de los fenómenos religiosos. Para Durkheim, a juicio de König, «una definición adecuada de religión, tal como la entiende una ciencia sin prejuicios, será la que logre abarcar lo universal del comportamiento religioso en los más diversos sistemas» (citado por J. Matthes (1971:23-24). En el estudio de la religión de Durkheim se dan varias interferencias entre la interpretación evolucionista y el análisis estructural-funcional. 
El análisis sociológico que Durkheim hace de la religión ha recibido fuertes críticas, entre otros de R. Aron (1970, V. II:), de M. Hill (1976:62-62), de Thomas Luckmann (1973:3-5), etc.. Pero, haciendo una valoración global de su pensamiento socio-religioso, se lo puede calificar de positivo, por haber inaugurado un tratamiento científico nuevo del hecho religioso, aunque con ambigüedades y deficiencias notables.

\section{Karl Marx}

A pesar de no haber tomado la religión como objeto de su estudio, sin embargo el pensamiento de Marx sobre la religión ha ejercido un gran influjo sobre la sociología de la religión. Sus ideas al respecto las toma de otros autores del siglo XIX y principalmente de Feuerbach que, en su obra «La esencia del cristianismo», defiende que la religión es un conjunto de ideas y valores creados por los hombres en el curso de su desarrollo cultural y erróneamente proyectados en fuerzas divinas o dioses (Feuerbach,1957). Mientras no entendamos la naturaleza de los símbolos religiosos que nosotros mismos hemos creado, dice Feuerbach, estamos condenados a ser prisioneros de fuerzas históricas que no podemos controlar.

Para Marx la religión es una de esas fuerzas que nos alienan, es un elemento más de la «superestructura» en manos de la «subestructura», del capital, para dominar a los trabajadores. En la medida en que los hombres se vean libres de la opresión económica, de la alienación y del miedo, la religión cederá el paso a un conocimiento real de la vida. Pero, mientras la sociedad permanezca dividida en clases de explotadores y explotados, la religión continuará siendo una forma de conciencia falsa que mistifica las relaciones de poder y explotación.

Marx califica a la religión de categoría histórica. La religión es una creación del hombre que surge en unas circunstancias históricas determinadas y que responde a una época concreta de la historia, pero que desaparecerá cuando dicha época llegue a su fin. Marx tomó de Feuerbach la idea de que no fue Dios quien creó al hombre, sino que fue el hombre quien creó a Dios a su imagen y semejanza. La religión primitivamente pudo cumplir la función de lograr la adaptación del hombre a su medio, pero luego se convirtió en religión institucionalizada, que, a través de la minoría dominante, defiende las relaciones y políticas existentes.

Para Marx «la religión es la teoría general de este mundo, su compendio enciclopédico, su lógica a nivel de pueblo, su «point d'honneur» espiritualista, su entusiasmo, su sanción moral, su complemento majestuoso, la razón general de su consuelo y de su justificación. Es la realización ilusoria del ser humano, porque éste carece de auténtica realidad. Por tanto, la lucha contra la religión es indirectamente lucha contra ese mundo cuyo aroma espiritual es la religión. La indigencia religiosa es, por una parte, expresión de la indigencia real y, por otra, protesta contra esta última. La religión es el suspiro de la criatura oprimida, el corazón de un mundo implacable, el espíritu de unas estructuras que carecen de él. 
Es el opio del pueblo», como dice Marx en su Crítica a la Filosofía del Derecho de Hegel. Si la religión es opio, alienación, la lucha contra la religión es lucha por la liberación y dignificación del hombre, por devolver a la humanidad su verdadera realidad, como concluye P.D. Dognin (1975:82-83), interpretando el pensamiento de Marx.

\section{Max Weber}

Contrariamente a lo que pensaba Marx, para Weber la religión es la única fuerza que capacita al hombre para redefinir el sentido de su vida, convirtiéndose en un enorme potencial para cambiar radicalmente la sociedad.

Weber también se diferencia de Durkheim y de su preocupación por la integración del individuo en la sociedad, al centrar su atención en descubrir los factores que impulsan la marcha de la sociedad. Weber trata de esclarecer el origen del mundo moderno occidental y las fuerzas que intervienen en su desarrollo. Este es el argumento central de su obra más conocida «La ética protestante y el espíritu del capitalismo».

Toda la teoría de Weber sobre el cambio social se fundamenta en el carisma y en la profecía de tipo religioso. Weber, como dice Baum (1973:9-10), admite que existe un tipo de religión tendente a reconciliar al hombre con su alienación, pero defiende que ha habido muchas épocas históricas en que la religión hizo que los hombres se levantaran contra su propia alienación, impulsándolos a transformar la sociedad.

Weber admite, por un lado, la posibilidad de una esencia de la religión y, por otro, «una forma concreta de actuación social» de la religión. A la hora de estudiar los fenómenos religiosos, prescinde de la primera posibilidad y reduce la sociología de la religión al estudio de la actuación motivada religiosamente. De ésta dice:

a) Que es una actuación con sentido, cuya comprensión sólo es posible a partir de las vivencias, representaciones y finalidades subjetivas del individuo.

b) Que en su estructura primigenia es una actuación intramundana, con lo cual el carácter sobrenatural y trascendente de la religión queda asociado al acto por el que el hombre da sentido a su actuar.

c) Que es una actuación por lo menos relativamente racional.

La vivencia religiosa, dice Weber, «es evidentemente irracional, como cualquier otra vivencia». Cuando se intenta dar una formulación racional de la misma, toda vivencia religiosa «pierde inmediatamente en contenido, tanto más cuanto más lejos se llegue en la formulación conceptual».

Sin embargo, las ideas religiosas ejercen una gran influencia en nuestra sociedad. Para explicar este hecho, Weber acude a dos argumentos: el primero de ellos es el postulado de coherencia: « Siempre existió, como trasfondo, a la hora de buscar respuestas a la irreprimible necesidad de salvación, una toma de posición respecto a algo, que, medido por referencia al mundo real, era experimentado como 
específicamente absurdo, lo que suponía que la estructura del mundo en su totalidad constituye, o debería constituir, un «cosmos» significativo, que, de una u otra forma, tiene un sentido» (Weber, 1972:344).

El segundo argumento lo toma del carácter utópico de las ideas religiosas frente a los datos de la vida cotidiana. Cuando los ideales religiosos se traducen en exigencias éticas, se crea una tensión entre la norma religiosa y la realidad.

La religión se convierte así, para Weber, en fuerza legitimadora de la existencia humana. Por una parte, existe un mundo real, empírico, que es captado por los sentidos, y por otra, un mundo invisible, pero igualmente real, que es captado por los ideales religiosos, y que es muy importante para comprender y mantener en orden el mundo visible.

Esta fuerza de la religión está vinculada al concepto weberiano de carisma, que consiste en una fuerza misteriosa que ostenta una persona y que atrae a los demás. La personalidad carismática se presenta como un ser humano dotado de poderes superiores, un hombre fuera de lo normal. Un portador típico del carisma religioso es el profeta que convoca a las personas a un mayor conocimiento de sí mismas y las impulsa a crear una nueva sociedad conforme a los ideales de justicia y de igualdad.

Para una recta comprensión del influjo de Weber en la sociología de la religión hay que tener en cuenta toda su amplia obra sociológica: sus investigaciones históricas sobre la ética protestante y el capitalismo, en las que trata de esclarecer el origen del mundo moderno y la génesis y desarrollo de Occidente; los estudios sobre la influencia de las ideas religiosas en la sociedad, sobre el carisma y el profeta portador del carisma, el misticismo y ascetismo, la racionalización y la secularización o la religión en un mundo secularizado, etc. (Weber,1973:328-329).

En resumen, podríamos decir que tanto Weber como Durkheim parten de lo religioso como de un dato definible y lo definen de acuerdo con lo que en la sociedad aparece y se comprende como religioso. Para Durkheim la religión no es más que un «datum» y la analiza desde puntos de vista estructurales y funcionales. Weber, por su parte, introduce el acto de dar «sentido» como elemento constitutivo de la actuación religiosa y utiliza el método comprensivo.

\section{LA SECULARIZACIÓN: LUCKMANN, BERGER Y TENBRUCK}

En los estudios más recientes sobre sociología de la religión se insiste en que el problema de la religión debe ser comprendido y tratado desde el punto de vista de la secularización. Según Friedrich Fürstenberg (1976), la secularización formaría parte de las tres grandes hipótesis directrices de la investigación religiosa, juntamente con las hipótesis de la «compensación» y de la «integración». La compensación se refiere al campo microsociológico, la integración al macrosociológico y la secularización abarca el campo de la transformación social. 
Desde la sociología se tiende a identificar la secularización como retroceso de lo religioso, como un proceso de desacralización de la historia. Lo mismo que en la historia antigua se registra la invasión de lo profano: mundo, sociedad, ciencia, arte, política, economía, etc, por parte de lo religioso, ahora se registra un proceso de desacralización de la historia moderna.

El concepto de secularización lo podríamos resumir, como hace Larri Schiner (1967:207-220), en los siguientes puntos:

a) Retroceso de la religión. Según varios autores (Milton Yinger, Charles Glock, A. Sorokin), la secularización es el proceso por el cual símbolos e instituciones, previamente aceptados como sagrados, pierden su carácter sacral.

b) Conformidad con este mundo. La sociedad, anteriormente conformada por lo religioso, con la secularización desvía su atención de lo sobrenatural y se interesa por las tareas pragmáticas del presente.

c) Desconexión de la sociedad frente a la religión. La sociedad se separa de la orientación religiosa y se constituye a sí misma en realidad autónoma, limitando la religión a la esfera privada.

d) Trasposición de creencias religiosas e instituciones. Las normas de conducta e instituciones, que en un tiempo fueron tenidas como de origen divino, son interpretadas ahora como fenómenos meramente culturales, de creación y responsabilidad exclusivamente humanas.

e) Desacralización del mundo. Se priva al mundo de su carácter sacral y el hombre y la naturaleza se convierten en objeto de explicación racional-causal de todo. Es el desencanto de la naturaleza, que dice Max Weber o la pérdida del sentido de lo sagrado, de que habla Mircea Eliade (1992).

f) Paso de una sociedad «sagrada» a una «secular». Este tipo de secularización forma parte de un concepto más general de «cambio social».

La secularización, pues, es un proceso filosófico-histórico-sociocultural, que tiene sus raíces en la reforma protestante, en la revolución científica del siglo XVIII y en la revolución industrial del siglo XIX, y que se manifiesta en el siglo XX como un fenómeno universal, al menos en Occidente. En este sentido la secularización significa tanto un proceso de descristianización o ruptura de la sociedad moderna con la sociedad medieval, como de desclesialización o emancipación frente al poder de la Iglesia institucional, oponiéndose a su abusivo autoritarismo en la vida de los hombres, para dar paso a un nuevo tipo de sociedad, la sociedad moderna.

Ahora bien, la secularización, al margen de esta tipología y tomada como perspectiva de análisis sociológico, nos ofrece unas coordenadas interpretativas de orientación programática, cuyas funciones principales, según Matthes (1971:84-96), son:

a) La posibilidad de una clasificación general a base de épocas y un cuadro analizable de referencias para las interpretaciones. «La secularización como categoría genealógica significa que, en un ámbito temporal concreto de la historia 
más reciente, se ha cumplido un proceso en el que el mundo actual se ha desprendido del pasado y se ha dotado a sí mismo de una forma cuya determinación hay que buscarla en su diversificación frente al pasado. El mundo pasado se presenta como cristiano-religioso en su totalidad; por el contrario, el mundo actual es un mundo secular, que, aunque por el momento dispone todavía de elementos cristianoreligiosos, sin embargo, éstos no lo caracterizan esencialmente. La reacción entre el mundo moderno y secular y su pasado cristiano-religioso es de carácter genético» (J.Matthes, 1971:85).

b) La definición y justificación de forma permanente de las nuevas situaciones de la autonomía y de la identidad historico-sociales. La crítica a la tradición cristiana hace que la religión se purifique, se especialice y se reduzca a grupos minoritarios y marginales.

c) El establecimiento de una relación inmediata entre el proceso de secularización, entendido como descristianización, y las transformaciones de las estructuras sociales de la época. En este sentido, el proceso de secularización mantiene una relación directa y causal con los procesos de industrialización y de urbanización; lo que supone que cuando una sociedad se industrializa y urbaniza, al mismo tiempo se registrará un proceso de secularización de la misma.

En resumen, la perspectiva de la secularización como sistema de coordenadas interpretativas contemporáneas está sirviendo de base a muchos sociólogos para su tarea investigadora de la religión. De entre los más representativos de esta perspectiva, citamos a Thomas Luckmann, Peter L. Berger y Friedrich H. Tenbruck.

\section{Thomas Luckmann}

Para Luckmann (1973:3-5) la secularización significa la pérdida progresiva de los valores representados por la religiosidad de la Iglesia, en cuanto elementos de integración y de legitimación del vivir cotidiano. Luckmann entiende la secularización como una consecuencia, tanto de la especialización institucional de la religión como de las transformaciones globales del orden social, en relación dialéctica.

La especialización de la religión, que se da en las sociedades que han alcanzado una notable complejidad en su estructura social, delimita los contenidos del cosmos sagrado, expresados en doctrinas y normas morales concretas y confiados a «expertos» socialmente designados.

Una primera consecuencia de esta situación es la incoherencia entre el modelo oficial y los sistemas individuales de significación. Esta incoherencia se hace más notable en situaciones de cambio; el modelo oficial tiende a cambiar a un ritmo mucho más lento que las condiciones sociales objetivas, codeterminantes de los principales sistemas individuales de significación. De aquí que la incoherencia de que habla Luckmann deba ser entendida en función de los factores que la aceleran o retardan, tales como: 
- La proporción y amplitud del cambio en las condiciones sociales objetivas.

- La mayor o menor rigidez del modelo oficial de religión.

- La distancia generacional de la socialización en el modelo oficial: a mayor distancia, menor incidencia.

- La situación diferencial de los individuos: sexo, edad, ocupación, clase social; en función de su situación ofrecerán una mayor o menor resistencia al cambio.

Paralelamente a la especialización en la religión, se produce un proceso también de especialización en la sociedad global, lo que fracciona la estructura social y modifica la relación del individuo con el orden social como un todo. Las distintas áreas de la actividad humana, al alcanzar un alto grado de especialización y autonomía, fueron creando cada una su autolegitimación y su versión de la concepción del mundo, al margen del cosmos sagrado. La falta de puntos de referencia universales y objetivos fomenta el proceso de secularización en la sociedad moderna.

Ante la pluralidad de concepciones cosmogónicas, es posible que el individuo se adhiera a alguna de estas versiones, pero es más probable, según Luckmann, que prevalezca una actitud de «consumidor» que escoge un producto determinado o que opta por crear su propio sistema individual. Este es el camino hacia la privatización de la religión, hacia la religión «invisible».

Sin embargo, la secularización, tal como la entiende Luckmann, no implica la supresión de los símbolos religiosos ni la desaparición de la religión, ya que la religión, tal como la entendía Durkheim y así lo cree también Luckmann, permanece necesariamente en el centro de la experiencia humana. El hombre siempre estará empeñado en la construcción de un cosmos sagrado para que su vida pueda tener significado y sentido último. De esta forma, la secularización total es imposible. Pero es cierto que determinadas formas de religión van perdiendo influencia social $\mathrm{y}$, en este sentido, se puede decir que están sufriendo un proceso de secularización.

Al disminuir la plausibilidad del modelo oficial de religión, bajo el impacto de la secularización, se produce entre los seguidores una crisis, en la que caben diversas posturas, que Luckmann tipifica de la forma siguiente:

1. Siempre habrá un grupo de individuos, cada vez más minoritario, que continúen asumiendo el modelo oficial, como si nada hubiera ocurrido: es una postura ingenua, que puede conducir a una marginación y a la ineficacia, en orden a resolver los problemas de la vida diaria.

2. Otros, cada vez más, acusarán el impacto del cambio social por diversas razones, lo que dificultará el mantenimientos del modelo oficial al pie de la letra. Dentro de esta situación se pueden dar varias posturas:

a) Algunos pueden adoptar unas actitudes que les llevan a mantener una religiosidad tradicional en determinadas esferas de la vida, mientras que en otras aceptan una actitud secular.

b) Otros, en cambio, reaccionarán con una actitud «consumidora», eligiendo eclécticamente los elementos necesarios para construir su propio sistema 
de significación última. Este es el caso del hombre de la religión «invisible», de una religión que no desaparece, pero que se retira a la esfera privada.

c) Según Luckmann (1973:84 y 97), se podría dar otro tipo de personas, que tenderían a hacer una elaboración reflexiva personal: son aquellos que consiguen armonizar una fidelidad al modelo oficial de su confesión religiosa, con la aceptación del cambio social en sus diversas manifestaciones.

\section{Peter L. Berger}

Para Berger (1971:46-50) la religión es el intento humano para establecer un cosmos sagrado, confrontado por el hombre como una realidad inmensamente poderosa y que constituye el intento de concebir el universo entero como algo humanamente significativo. La religión, al ser tomada como un criterio estable de realidad «última», se convierte en fuente de legitimación, que se ejerce de formas diversas a lo largo de la historia.

Para que la religión ejerza su función legitimadora, dice Berger, es necesario que cuente con el reconocimiento de la base social que intenta legitimar; es decir, necesita de una «estructura de plausibilidad». Cuanto más firme sea la estructura de plausibilidad, mejor asentado estará el mundo que en ella se apoya y, por lo mismo, necesitará de menos justificación. Esto quiere decir que, cuando es una sociedad entera la que acepta un mundo religiosamente legitimado, todos los procesos sociales importantes están al servicio de la confirmación de ese mundo y, entonces, su sistema religioso particular tiene posibilidad de mantenerse como un monopolio con garantías de éxito (Berger, 1971:78).

Pero esta situación cambia radicalmente cuando diferentes sistemas compiten en la presentación de ofertas de significado y de legitimación, es decir, cuando aparece la sociedad moderna, diferenciada y pluralista, en la que juega un papel importante la racionalización entendida en sentido weberiano. La racionalización aplicada a la producción de recursos da lugar a la industrialización, en la que la técnica capacita al hombre para transformar la naturaleza a su medida, en vez de acomodarse a sus ritmos, como lo hacía antiguamente.

La aplicación masiva de la técnica produce división del trabajo, de la que se deriva la especialización, entendida no solamente desde un punto de vista funcional, sino también como autonomía de los ámbitos especializados. De esta forma, diversas esferas de la vida humana se van emancipando del centralismo monopolizador de la religión. Estas esferas autónomas, que actúan como «islas liberadas», llegan a crear un nuevo tipo de sociedad: la sociedad pluralista y diferenciada. En este tipo de sociedad, las condiciones objetivas socio-estructurales amenazan el poder integrador y monopolizador que ejercía la religión en la sociedad no especializada.

La religión, sin embargo, no deja de existir en la sociedad pluralista: cambia de localización, pasando a la esfera privada, donde aún cuenta con una base de sustentación. Por otra parte, los productos religiosos dejan de tener carácter 
obligatorio y quedan sometidos a las leyes de mercado: deben ser expuestos y ofertados. Los responsables religiosos deben «racionalizar» sus productos, tanto en su presentación como en sus contenidos. En vez de un mensaje nuevo en una sociedad vieja, ahora se trata de anunciar un mensaje viejo en una sociedad nueva.

Por otra parte, en esta situación de mercado interviene un nuevo elemento: el control del consumidor sobre el producto. La religión ya no puede ser impuesta, sino que tiene que ser ofertada en el mercado, para lo que ha de tener en cuenta las necesidades y problemas de los potenciales consumidores (Berger,1971:207). En una sociedad secularizada, carente de estructuras de plausibilidad, los antiguos contenidos religiosos sólo se podrán mantener en la conciencia del individuo como meras «preferencias religiosas» con la consiguiente relativización de lo religioso.

\section{Friedrich H. Tenbruck}

Tenbruck, en su ensayo socio-religioso, se distancia de la tesis de la secularización global y, en vez de formular una teoría monocausal de lo que él intencionadamente llama desclesialización, fija una «constelación sociológica de condiciones que dan lugar a diversas realizaciones históricas y a factores individuales eficaces», como dice Matthes en su obra «Introducción a la sociología de la religión» (1971:107-108).

Tenbruck tiene una doble visión de la desclesialización. Por una parte, la entiende como un producto histórico, como el desmembramiento de una organización social, la Iglesia, que habría llegado con el fin del «orden preindustrial» o con la llegada del «orden industrial», lo que significa la pérdida de significación de la religión organizada en cuanto medio de control social. Los individuos ya no se sienten constreñidos por la Iglesia en sus intereses jurídicos, profesionales, económicos y sociales.

Por otro lado, la desclesialización, para Tenbruck, supone la pérdida de las funciones de naturaleza individual o social de la religión, que vienen dadas en forma de fe, culto y ethos. Una de estas funciones sería la estabilización de la personalidad en momentos difíciles y críticos por medio de la autocomprensión general.

En la sociedad moderna, donde abundan la diversidad y heterogeneidad de grupos y en la que el individuo pertenece a varios grupos a la vez: sindicatos, partidos políticos, asociaciones culturales, etc., los sentimientos religiosos quedan relegados a la participación en grupos especiales. Pero muchas veces la identificación con un grupo implica el extrañamiento de otro. De esta forma, la desclesialización aparece como un distanciamiento entre los grupos sociales y religiosos, que en la sociedad preindustrial actuaban juntos.

Resumiendo el pensamiento socio-religioso de Tenbruck, podríamos decir que en la medida en que la religión se aparta de la comunicación social y pierde presencia en la sociedad, en esa misma medida pierde para los individuos no sólo sus funciones, sino también su realidad. 
Como hemos visto, Luckmann, Berger y Tenbruck, partiendo de la misma perspectiva de la secularización, aunque entendida de distinta manera, llegan a la conclusión común de que la religión, en la sociedad moderna, tiende a privatizarse. Las posiciones de estos tres autores, por una parte, pueden entenderse como continuidad de las de Durkheim y Weber, y, por otra parte, abren un nuevo campo de trabajo.

\section{EL «MODELO GLOBAL» POSTMODERNO DE KEN WILLBER.}

Teniendo en cuenta el contexto socio-histórico y cultural en que se ha desarrollado la primera etapa de la sociología, era de prever que los primeros estudios sociológicos sobre la religión estuvieran profundamente influenciados por las corrientes científicas dominantes: positivismo (Comte), mecanicismoevolucionismo (Spencer), materialismo dialéctico (Marx), dando como resultado unos análisis excesivamente reduccionistas. Así es como lo entiende Ken Wilber.

Estos planteamientos sociológicos reduccionistas han sido corregidos, al menos en parte, como dice Wilber (1988:21), por los sociólogos posteriores, al introducir otras perspectivas de análisis, como el funcionalismo (Durkheim y Parsons), el estudio del significado de la acción social y de los actos mentales (Weber y Freüd), el secularismo (Luckmann, Berger, Tenbruck).

Sin embargo, para Wilber (1988:22) la sociología todavía no se ha abierto a las preocupaciones contenidas en la filosofía perenne, y las perspectivas hasta ahora utilizadas sirven para explicar un tipo de religiosidad concreta, como puede ser: la «religiosidad burguesa» (Marx), la «religiosidad neurótica» (Freüd), la funcionalidad de la religión (Durkheim), la «religiosidad secularizada» (Luckmann), pero no toda la religiosidad existente. Por ello, Wilber trata de corregir los errores de la sociología del pasado y ampliar el campo del análisis socio-religioso a todas las estructuras, dimensiones y niveles de desarrollo humano sin limitaciones de ningún tipo. Para ello, elabora un marco teórico global, que pretende aplicar desde lo que él llama la «sociología trascendental».

En el nuevo modelo de análisis sociológico, Wilber parte de la premisa de que el hecho religioso está vinculado de forma esencial a la naturaleza humana; ya que, al estudiar las distintas manifestaciones de lo social, nos encontramos siempre con el hombre como sujeto y objeto de todo lo social. Pero el hombre es a la vez «mundo» (corporeidad), «mente» (conciencia) y «espíritu» (trascendencia). Prescindir de alguna de sus dimensiones o niveles de realización supondría caer en un nuevo reduccionismo antropológico.

Wilber, en sus numerosas publicaciones sobre el tema de la religión, ha logrado integrar los principales sistemas psicológicos y religiosos del mundo. En su obra, El proyecto Atman (1981), puede verse un modelo de psicología del desarrollo que comprende todas las etapas del proceso evolutivo humano; en $U p$ from Eden (1982) aplica el mismo método a la evolución humana en general; y en Un dios sociable (1988) 
interpreta los diversos tipos de religión/religiosidad predominantes a lo largo y ancho de la sociedad humana, dadas su interdependencia e interrelación sociales. Con la aplicación de este modelo, Wilber cree haber superado todos los reduccionismos de las interpretaciones sociológicas anteriores, como dice el Prf. Fernández, F. (1994 y 1996).

Otra premisa de la «sociología trascendental» de Wilber es la creencia de que existe una jerarquía en el desarrollo social humano, a la que corresponde una jerarquía en el desarrollo religioso, que permite analizar estructuralmente diversas expresiones socio-religiosas y asignarlas su grado de «legitimidad» y de «autenticidad» (1996).

El desarrollo social humano, en el modelo de Wilber, comprende siete niveles distintos: arcaico, mágico, mítico, racional, psíquico, sutil y causal. Los tres primeros niveles se corresponden con la primera etapa del desarrollo humano, caracterizada por un estado general de pre-conciencia y por una religiosidad popular. El nivel «racional» corresponde a la segunda etapa de desarrollo, que se caracteriza por la conciencia del «sujeto humano», del «yo-tu», del «otro», de lo social, y por una religiosidad racionalizada e interiorizada. La tercera etapa comprende los niveles psicológico, sutil y causal, y se caracteriza por un estado general de transconciencia (transpersonal) y una religiosidad transracional, mística y de amor pleno o identificación con lo divino.

En conclusión, Wilber considera que la auténtica religiosidad se da en los niveles de desarrollo correspondientes a la tercera etapa, la transracional, y que el grado de validez de cualquier tipo de religión puede juzgarse teniendo en cuenta su «grado de legitimidad» o significatividad desarrollada en el nivel correspondiente, y su «grado de autenticidad» o capacidad de cambio de un nivel a otro en sentido ascendente.

\section{CONCLUSIÓN}

Al comienzo de mi trabajo me propuse justificar que el hecho religioso es un hecho social y que la religión, por consiguiente, es objeto de estudio de la sociología. Por otra parte, de forma retrospectiva y esquemática, he presentado las distintas perspectivas de análisis de la religión, citando entre los autores clásicos a Comte, Durkheim, Marx y Weber, entre los modernos a Luckmann, Berger y Tenbruck, y como representante de los postmodernos a K. Willber. Ahora, a modo de síntesis, reseño los puntos más importantes de mi estudio:

Primero.- El fenómeno religioso es considerado unánimemente por la sociología como un hecho social de importancia.

Segundo.- Las religión, además de los elementos trascendentes, cuenta con elementos observables, medibles y comparables, y como tales pertenecientes al campo de estudio de la sociología.

Tercero.- Han existido distintos posicionamientos en el campo de la sociología para acercarse al estudio de la religión, de los que cito como perspectivas 
de análisis más importantes: el positivismo (Comte), el funcionalismo, seguido por E. Durkheim y M. Weber, el materialismo dialéctico (Marx), la secularización, cuyos principales representantes son Luckmann, P.Berger y Tenbruck, y en último lugar, como globalizante, la aportación de Wilber.

Cuarto.- En clave funcionalista, lo que interesa en el estudio de la religión es la comprensión de la incidencia significativa de la religión en la vida social del hombre.

Quinto.- La secularización, desde la sociología, es considerada como un proceso dialéctico entre religión y sociedad, orientado a la emancipación de esta última del influjo y control por parte de la religión. De la secularización se han creado distintas tipologías, coincidentes todas ellas en señalar como nota dominante la desacralización de la historia.

Sexto.- Como punto final quiero decir que, a pesar de los pronósticos de los primeros sociólogos sobre el fin inmediato de la religión; a pesar del proceso de secularización extendido por todo Occidente; a pesar del dominio del pensamiento racionalista sobre muchos campos de la vida social; sin embargo todavía hoy hay millones de personas que siguen fieles a las religiones universales o tradicionales y otros miles de personas que están buscando respuesta a sus interrogantes en nuevas iglesias y sectas. Este hecho es el que me lleva a afirmar que la religión continuará siendo un fenómeno social en el futuro y, por lo mismo, objeto de estudio para la Sociología. Mientras la ciencia no conteste a interrogantes fundamentales para el hombre, como son su origen y destino, el significado de la vida, el más allá, etc., la religión continuará teniendo una función importante en la sociedad, seguirá siendo considerada necesaria para el hombre y de interés para el científico social. 


\section{BIBLIOGRAFÍA}

ARON, R., (1970): Las etapas del pensamiento sociológico, Siglo XXI, Buenos Aires.

BAUM,G., ( 1973): «La persistencia de lo sagrado», en Concilium, 81, p.9-10. CLAUSSEN, D., ( 1995): «Un mundo desencantado, una liberación malograda», en Debats, 51, pp. 70-76.

COMTE, A. Y SAINT-SIMON, H.: Plan de operaciones cientificas necesarias para la reorganización de la sociedad.

DOGNIN, P.H., (1975): Introducción a Karl Marx, Cedial, Bogotá.

DURKHEIM, E., ( 1899): «De la definition des phenomenes religieux», en Année Sociologique, II.

ELIADE, M.,(1992): Mito y realidad, Labor, Barcelona.

FERNÁNDEZ FERNÁNDEZ, F.,(1996): «El hecho religiodo: necesidad de un marco antropológico global como referencia de un diagnóstico sociológico integral e integrado», en Sociedad y Utopía, Rev. de Ciencias Sociales, 8, Fac. de CC. Políticas y Sociología, Madrid, p.77.

FERNÁNDEZ FERNÁNDEZ, F,.( 1994) : «Los niveles del desarrollo social humano y su correspondiente tipo de religiosidad: modelo sociológico general de Ken Willber», en Sociedad y Utopía, Rev. de Ciencias Sociales, 4, Madrid, p.206.

FÜRSTENBERG, F., (1976): Sociología de la religión, Sígueme, Salamanca GODDIJN, H.W., (1973): Sociología de la Religión y de la Iglesia, Carlos Lohlé, Buenos Aires.

HILL, M., (1976): Sociología de la Religión,Cristiandad, Madrid.

LUCKMANN, TH., (1973): La religión invisible, Sígueme, Salamanca.

MARDONES, J.M., ( 1996): «La desinstitucionalización religiosa», en Sociedad y Utopía, 8, pp. 95-113.

MASA, M., ( 1996): «¿Secularización? ¿Privatización de la religión?: Aproximaciones recientes en sociología, en Inguruak, 14:, pp. 105-126.

MATTHES, J., (1971): Introducción a la sociología de la religión:

Religión y sociedad, Alianza, Madrid.

MERTON, R., (1986): Social Theory and Social Structure, Free Pres, Nueva York.

MILANESI,G., Y BAJZEK,J. (1993): Sociología de la religión, C.C.S., Madrid. PRADES, J.A., (1998): «Lecturas Historiográfica y Heurística de los Clásicos de la sociología», en Revista Internacional de Sociología, 1998, 21: 195-210.

RITZER,G., (1995): Teoría sociológica clásica. V.I., McGraw Hill, Madrid. SÁNCHEZ CAPDEQUI, C., (1998): «Las formas de la religión en la sociedad moderna», en Papers, Revista de Sociología, 54, pp. 169-185.

SCHINER,L., (1967): «The Concept of Secularization», en Study of Religion, 6, p. 207-220. 
TRIAS, E., ( 1999): «Religión ilustrada, razón secularizada», en Archipiélago,36, pp.43-45.

WACH, J., (1958): Sociology of Religion, Nueva York.

WEBER, M., (1969): La ética protestante y el espíritu del capitalismo, Península, Barcelona. (1972): Economía y Sociedad, Fondo de Cultura Económica, México.(1972): Ensayos de sociología contemporánea, Martínez Roca, Barcelona. WILBER, K., (1988): Un Dios sociable. Introducción a la sociología trascendental, Kairós, Barcelona. 